Revista Electrónica Complutense de Investigación en Educación Musical ISSNe: 1698-7454

http://dx.doi.org/10.5209/RECIEM.58844

\title{
Cremades, R. (Coord) (2017) Didáctica de la educación musical en primaria. Madrid: Paraninfo
}

El libro está coordinado por el autor R. Cremades, profesor Contratado Doctor de la Universidad Complutense de Madrid que además es uno de los autores del libro. Colaboran otros autores especialistas y figuras relevantes en el ámbito de la Educación Musical en España, todo ellos docentes e investigadores de la Universidad Complutense y la Autónoma de Madrid. Se compone de ocho capítulos uniformemente estructurados que abordan aspectos generales y específicos del área de didáctica de la música, como fundamentación psicopedagógica y programaciones que se acogen a la legislación y normativa actual de educación primaria.

El primer capítulo lo inicia A. Morales. Describe las ideas psicopedagógicas más relevantes, realizando un breve recorrido histórico por los autores que han contribuido a entender la educación musical como parte importante en el desarrollo integral de la persona. Se muestran principios teóricos, además de aspectos teórico-prácticos del proceso enseñanza aprendizaje, como estrategias metodológicas en educación musical.

A continuación, se presenta el segundo capítulo, en el que se aborda la programación en el aula de Música. En este capítulo participa esta misma autora junto con otros autores como M.J del Olmo, M. Román y S. Toboso. Como introducción al capítulo se muestra una propuesta de contenidos musicales de una programación didáctica en formato de tabla. Se exponen la definición de programación y las diferentes etapas en la elaboración de una programación, metodologías, contenidos, competencias, objetivos y evaluación de la misma. Se relacionan los objetivos con los expuestos en la taxonomía de Bloom (1979) en relación con el saber, el saber-hacer y saber ser-estar referidos a los ámbitos cognitivo, afectivo-relacional y psicomotor. Finalmente, se muestra un ejemplo de U.D. Sin duda el relacionar los objetivos de la programación con los objetivos de la taxonomía de Bloom es un acierto, pues las enseñanzas artísticas en Educación Primaria tienen un componente altamente procedimental en el que "aplicar" es una forma fundamental de mostrar los conocimientos aprendidos además de adquirir y desarrollar las habilidades en los distintos ámbitos.

Los siguientes capítulos giran en torno a contenidos musicales específicos. El capítulo tres trata la audición comprensiva en la Educación primaria. Los autores de este capítulo son B. Lizaso y R. Cremades. Se muestran distintas actitudes con las que puede posicionarse el oyente y además nos indica los diferentes significados que se pueden otorgar a la música escuchada. En la percepción musical influyen muchas variables musicales y socioculturales. Dentro de los factores socioculturales hay que tener presente la enculturación y la experiencia musical como factores que influyen en esa percepción (Tizón 2017). Finalmente, el capítulo nos expone diferentes metodologías en el proceso de la audición musical, finalizando con una propuesta de aplicación en el aula. 
El capítulo cuatro tiene como autores a D. García-Gil e I. Sustaeta. Se continúan abordando los contenidos musicales específicos, en este caso, la voz. Se introduce la voz, no sólo desde la interpretación, sino que la vincula con la escucha y con la danza. Se muestran estrategias para la enseñanza del canto, así como selección del repertorio y propuestas didácticas. En la introducción los autores relacionan la voz y la canción con los bloques del marco curricular de Educación Musical Primaria. Lo muestran de forma gráfica en la figura 4.1. relacionando los bloques interpretación, canción, escucha y danza. No obstante, y como sugerencia se propone insertar el término "movimiento" dentro del bloque danza, puesto que los autores introducen actividades de movimiento (que no de danza) incluidas, por ejemplo, en la tabla 4.14. En estas actividades se proponen movimientos como forma de expresión musical que es el fin educativo que plantea, por ejemplo, Dalcroze. Además, se presentan "canciones danzadas" como aquellas en las que el texto cantado se acompaña de movimientos sencillos, circulares, lineales, etc. (Martín 2005). En este sentido, sería conveniente definir y diferenciar el concepto de "movimiento" del de "Danza", pues además ambos conceptos se pueden abordar desde diferentes perspectivas.

Los instrumentos, son la parte principal del contenido musical que se expone en el capítulo cinco. A. Morales señala la importancia de la práctica instrumental en el aula, el lenguaje de la música en la interpretación instrumental, el desarrollo de la percepción, la expresión musical y las capacidades psicomotrices. También expone las familias de instrumentos y los instrumentos Orff. El apartado 5.4 propone recursos para la práctica instrumental en el aula y finaliza con el apartado 5.5, en el que se presentan pautas de actuación para los maestros especialistas incidiendo en el carácter procedimental de la práctica.

El último capítulo que alude a contenidos específicos musicales es el capítulo seis, con el movimiento y la danza en educación musical. Está escrito por P. Ríos. En este capítulo se muestra el movimiento y la danza en el currículo de primaria, la importancia de la danza en el ámbito educativo y el movimiento y la danza como forma de enseñar música, aludiendo a autores como Dalcroze, Willems y Orff. Finaliza el capítulo realizando una propuesta de dos danzas para su introducción en el aula. Cabe destacar la separación tan acertada que realiza entre el movimiento y la danza como forma de expresión musical representada por los citados autores, diferenciándolo de la expresión corporal y la danza educativa, aunque es necesario señalar que la danza, aparte de ser una forma de expresión musical, es también una forma de expresión corporal. En el apartado de la danza en la educación aparecen autores relevantes como Laban y Maschat. Quizás, el hecho de diferenciar el movimiento o la danza como forma de expresión musical o como forma de expresión corporal, nos ofrece las pautas para entenderlo como fin o como medio. Laban y Dalcroze, por ejemplo, introducen en sus metodologías el movimiento como forma de educación, pero con fines muy distintos: Dalcroze utiliza el movimiento corporal como forma de expresión musical y Laban como forma de expresión corporal para desarrollar la creatividad en el aula (Carrasco 2012). En el último apartado del capítulo se proponen algunas sugerencias de mejora. En el apartado 6.6, la autora realiza dos propuestas de introducción de danza en la escuela, una en base a la interpretación y otra a la creación. Se describen movimientos y una danza con palabras e incluso se propone una notación musical adaptada al baile. En lo referente a la descripción con palabras, se sugiere referenciar algún enlace de vídeo, pues tal y como diría Laban (1994), "descripciones accidentales en palabras, que son inadecuadas para ofrecer un cuadro 
de movimiento, o en coreografías que en realidad nadie puede descifrar" (p.14). Lo mismo ocurre con la notación propuesta, la herramienta del vídeo/instrucción directa es hasta ahora la más efectiva a la hora de entender, comprender y aprender un movimiento o danza, sobre todo en descripciones concretas, pues ya existen propuestas de notación en danza precisas como las de Laban o Benech y ninguna de ellas son eficaces a la hora del aprendizaje de un movimiento o danza.

El capítulo siete aborda la Música y TIC en la Educación Primaria. M. Román comienza con una introducción sobre el impacto de las nuevas tecnologías. Continúa con la importancia de la formación del profesorado en el uso de las TIC y la contribución en la Educación Primaria, las necesidades tecnológicas en un aula de primaria y una categorización de las aplicaciones musicales en: editores de partituras, secuenciadores, editores de sonido, interpretadores, materiales didácticos y aplicaciones multimedia.

El último capítulo del libro atiende a la diversidad en el aula. M.J. del Olmo, presenta las dificultades que pueden presentar los alumnos con necesidades educativas especiales y cómo se trata este aspecto en la LOMCE. Así mismo, aborda la musicoterapia y los usos y funciones terapéuticas de música en el ámbito educativo. En el apartado 8.3 la autora muestra aspectos musicales como el ritmo, la voz, los instrumentos y el movimiento para trabajar a través de la musicoterapia. Es en concreto en el apartado 8.3.4., donde se hace referencia al movimiento y a la danza. En este apartado, propone propuestas de actividades de movimiento y danza como formas de expresión necesarias en educación musical, para los alumnos de necesidades educativas especiales. Bien es cierto, como hemos dicho anteriormente, que tanto el movimiento como la danza pueden situarse "a caballo" entre la disciplina de educación musical y la de educación corporal, sin embargo, en este apartado, se expone la danza también como forma de expresión corporal y en este sentido, sería más conveniente enmarcarlo en el contexto de la danza-terapia. Finaliza el capítulo con el apartado de propuestas didáctica para el aula mostrando diferentes propuestas de intervención según la deficiencia educativa.

Sin duda, el libro Didáctica de la educación musical en primaria se presenta como un manual referente para los maestros de educación musical primaria. Las sugerencias y aportaciones de mejora se centran en aspectos de movimiento y danza que, por otra parte, son materias que necesitan abordarse desde una mayor profundidad, pues tal y como expone Laban en su libro Danza educativa moderna (1994), "en comparación con lo que se conoce a este respecto sobre las demás artes, nuestro conocimiento en el campo del arte del movimiento es harto exiguo" (p. 13).

El manual nos ofrece una gran variedad de recursos didácticos para que el maestro de primaria pueda aplicarlo en el aula, además, los recursos que ofrece, están fundamentados en teorías y autores relevantes del campo de la pedagogía y educación musical que, a su vez, se acogen a la normativa y legislación vigente.

\section{Referencias bibliográficas}

Carrasco, A. M. V. (2012) Jaques Dalcroze y Rudolf von Laban: algunos datos sobre su concepción del movimiento. Artseduca, 3, 30-35. https://dialnet.unirioja.es/servlet/ articulo? codigo $=4016900$

Laban R. (1994) Danza educativa moderna. Barcelona: Paidós Ibérica 
Martín M. J. (2005) Del movimiento a la danza en la educación musical. Educatio siglo XXI: Revista de la Facultad de Educación, 23, 125-140. https://dialnet.unirioja.es/servlet/ articulo? codigo $=2040498$

Tizón M. (2017) Enculturación, música y emociones. Revista Electrónica Complutense de investigación en Educación Musical, 14, 187-211. http://dx.doi.org/10.5209/RECIEM.52430

Rosa de las Heras-Fernández rosa.heras@unir.net 